\title{
SERIOUS GAME PARA REABILITAÇÃO DE CADEIRANTES UTILIZANDO KINECT E REALIDADE VIRTUAL
}

\author{
L. C. Oliveira ${ }^{1,2}$, T. C. F. Gomes ${ }^{2}$, F. G. Fernandes ${ }^{1}$ e E. C. Oliveira ${ }^{1,2}$ \\ ${ }^{1}$ Universidade Federal de Uberlândia - UFU, Uberlândia - MG, Brasil \\ ${ }^{2}$ Universidade de Uberaba - UNIUBE, Uberlândia - MG, Brasil \\ e-mail: lchagasoliveira@gmail.com
}

\begin{abstract}
Resumo: Recentemente, observa-se uma grande demanda por jogos e lazer na sociedade. Porém, o usuário não se contenta apenas com a forma de jogar, o que levou pesquisadores e inovadores a uma melhor interação natural entre homem e máquina. A evolução dos jogos tem sido algo surpreendente, não apenas em gráficos e design, mas também em sua forma de jogar, passando para uma fase na qual a interação entre homem e máquina se torna mais natural, podendo-se jogar apenas por meio de gestos, áudio ou posições corporais. Com a crescente popularização desses jogos, surgiu a necessidade e oportunidade de se incluir de maneira eficaz os portadores de deficiência física, além de trazer junto com os jogos esportivos uma maneira mais prática de se aplicar a reabilitação desses usuários. Este trabalho mostra uma aplicação utilizando Realidade Virtual ou Virtualidade Aumentada para inclusão e reabilitação de pessoas com defíciência física cadeirantes, por meio do Microsoft Kinect.

Palavras-chave: cadeirantes, fisioterapia, kinect, serious game, tecnologia assistiva.
\end{abstract}

\begin{abstract}
Recently, there is a great demand for games and leisure in society. However, the user is not satisfied with just how to play, leading researchers and innovators to better natural interaction between man and machine. The evolution of games has been somewhat surprising, not only in graphics and design, but also in their style of play, moving to a stage where the interaction between man and machine becomes more natural and can be played only by gestures, audio or body positions. With the growing popularity of these games came the need and opportunity to include effectively the physically disabled, and bring along with sports games way more practical to apply the rehabilitation of users. This work shows an application using Virtual Reality or Augmented Virtuality for inclusion and rehabilitation of people with disabilities wheelchair through the Microsoft Kinect.
\end{abstract}

Keywords: wheelchair, physical therapy, kinect, serious game, assistive technology.

\section{Introdução}

A inclusão social é uma preocupação para todos, evitar a exclusão por deficiência é algo que não pode ser ignorado. A necessidade de se incluir o deficiente nos atos sociais é cada vez maior. Sendo necessário, assim, o esforço de pesquisadores e estudiosos para que essa meta seja uma realidade para que todos possam ser inclusos na sociedade.

Desse modo, a Tecnologia Assistiva (TA) deve ser entendida como um auxílio que promoverá a ampliação de uma habilidade funcional deficitária ou possibilitará a realização da função desejada e que se encontra impedida por circunstância de deficiência ou pelo envelhecimento. Podemos, então, dizer que o objetivo maior da TA é proporcionar à pessoa com deficiência maior independência, qualidade de vida e inclusão social, através da ampliação de sua comunicação, mobilidade, controle de seu ambiente, habilidades de seu aprendizado e trabalho. [1].

Além disso, o desenvolvimento tecnológico vem buscando alcançar uma melhor interação entre o homem e a máquina, chamada de interação natural. Interação Natural (IN) é considerada um conceito, quase ciência, que estuda formas de o homem interagir com dispositivos eletrônicos através dos cinco sentidos do ser humano, seja através de gestos, comandos de voz, movimentos e expressões corporais ou deteç̧ão e identificação de partes do corpo humano como rosto, mão, polegar, retina, articulações, entre outros [2].

Nessa perspectiva, este trabalho mostra um jogo de Realidade Virtual esportivo para cadeirantes, que proporciona motivação ao deficiente físico, por se tratar de algo divertido que passa, muita das vezes, por algum tipo de problema emocional. A aplicação também permite a movimentação, pois o jogo é executado através da tecnologia Kinect, que captura o movimento do usuário colocando-o de forma virtual dentro do jogo, onde ele terá que se movimentar para que possa jogar. $\mathrm{O}$ jogo é adaptado ao deficiente físico para que possa interagir com o jogo, em que o usuário irá vê-lo na tela como cadeirante, utilizando as habilidades que não ultrapassam seus limites, para que possa cumprir os objetivos do jogo.

\section{Materiais e métodos}

Com relação aos aspectos metodológicos e tecnológicos, para a implementação desse jogo foi utilizado a Realidade Virtual e o sensor Kinect para captura dos movimentos. A linguagem utilizada foi o C\#, dispondo de animações e interações com o usuário. 
Além disso, foi utilizada a plataforma XNA da Microsoft, visando criar um jogo atrativo para melhor uso do cadeirante. A ferramenta utilizada para engine de jogos foi a Unity $3 D$.

Realidade Virtual (RV) é um sistema computacional usado para criar um ambiente artificial, no qual o usuário tem a impressão de não somente estar dentro deste ambiente, mas também habilitado, com a capacidade de navegar no mesmo, interagindo com seus objetos de maneira intuitiva e natural. As tecnologias de RV fazem com que o usuário seja completamente imerso em um ambiente sintético. Enquanto está imerso, o usuário não pode ver o mundo real em volta dele [3].

O sensor Kinect é uma grande inovação nos últimos anos, traz de uma maneira mais eficaz a interação homem-máquina. Possibilita que o usuário interaja com o dispositivo apenas com gestos e movimentos sem a necessidade de um controle, esses movimentos são capturados por câmeras e sensores trazendo um jogo mais real para a vida dos usuários [4].

C\# é uma linguagem de programação que foi baseada em $\mathrm{C}++$ e sofreu grandes influencias da linguagem de programação Java. A linguagem de programação $\mathrm{C \#}$ é orientada a objetos e é considera como simples e de grande desempenho, pois aproveita de características de outras linguagens que foi originada [5].

Microsoft XNA é um framework gratuito e robusto com interface amigável desenvolvido pela Microsoft para criar jogos tanto para computador, console XBox 360 e Windows Phone 7. XNA foi projetado pensando nas pessoas que querem fazer seus próprios jogos e acham complicado trabalhar com Direct $X$, Open $G L$ e/ou outras APIs (Interfaces de Programação de Aplicação) [6].

O Unity $3 D$ é uma poderosa ferramenta de desenvolvimento de games, conta com várias ferramentas de modelagem e estrutura que auxilia a criação de jogos. Além da possibilidade da criação de cenários variáveis, a ferramenta permite o desenvolvimento de programação para a lógica do jogo em Java Script e C\# [7].

A conexão do Unity com o Kinect fez com que as entradas do jogo fossem feitas por gestos, isto é, substituindo mouse, teclado ou joystick por ações reais do personagem usuário, o que foi de extrema importância no quesito de reabilitação por movimento do corpo.

No desenvolvimento do jogo de reabilitação para cadeirantes, foi estudada a estrutura física do Kinect, bem como sensor infravermelho, sensor de distância, as câmeras e como o Kinect captura gestos e movimentos da pessoa e passa para a programação.

Para captura do movimento, o sensor Kinect utiliza de um código de programação para ler os movimentos do usuário e passa por meio do código. Em seguida, o sistema detecta o movimento necessário para que a cadeira possa se movimentar na pista em direção a linha de chegada.

Existem dois tipos de ação: as que não interferem no jogo, como balançar de cabeça, entre outros que não modificará a posição do avatar no jogo, e as ações cujo movimento modifica o estado do jogador no jogo.

O gesto necessário para movimentação do corredor cadeirante na pista é o das mãos como se estivesse andando em uma cadeira de rodas, ou seja, colocar a mão reta verticalmente com o corpo, fechar a mão e movimentá-la para frente, repetindo os movimentos para locomoção no jogo.

Para detectar esse movimento de locomoção, foi necessário criar um algoritmo para rastrear os movimentos do cadeirante e comparar com os movimentos para o desenvolvimento do usuário no jogo. O software deve conter uma classe para rastrear e identificar os gestos. Este gesto possui três estados: não identificado, em execução e identificado.

Para que os gestos sejam válidos, é necessário realizar um cálculo de análise do ângulo do braço para saber se o usuário está na posição correta de impulso da cadeira de rodas. Se a posição for válida, então a cadeira de rodas no jogo se movimenta de acordo com os gestos na pista, e assim, sucessivamente, até que chegue ao seu final.

A plataforma XNA foi escolhida por oferecer fácil desenvolvimento, além de proporcionar ferramentas de desenvolvimentos de grande utilidade e que funciona totalmente num ambiente de execução gerenciado.

Ela é uma interface que proporciona que o jogador (usuário), se comunique no jogo com o Microsoft Kinect. O XNA tem várias camadas que permitem ao programador lidar diretamente com a camada gráfica do dispositivo, incluindo métodos, propriedades e eventos que permitem visualizar e modificar a camada pretendida.

Uma propriedade característica e bastante interessante da plataforma de desenvolvimento XNA é a maneira como ele permite importar qualquer tipo de conteúdo para desenvolvimento da aplicação. Dessa maneira, não é necessário fazer manualmente todo o processo de carregar e armazenar conteúdos, nem verificar se existem bibliotecas corretas para importação e execução dos mesmos, entre outros detalhes a serem resolvidos.

O gerenciador de conteúdo do XNA realiza todo o processo, fazendo com que economize tempo e linhas de código, tornando-se assim uma ferramenta bastante agradável de se utilizar. Na prática, o que ele faz é importar conteúdos, processá-los com o compilador de conteúdo e gerar um arquivo com extensão. XNB que será utilizado pelo jogo.

A lógica central do jogo é a movimentação do jogador através dos gestos necessários. Para isso, foram utilizadas algumas funcionalidades e métodos. Algumas classes e métodos são apresentadas a seguir utilizando a linguagem $\mathrm{CH}$ :

- Initialize() - Inicialização do jogo ();

- LoadContent( () - Inicializa e carrega recursos gráficos ();

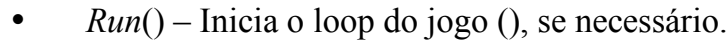


- Update() - Captura os comandos do jogador, realiza cálculos e testa o critério de fim de jogo ();

- $\operatorname{Draw}()-$ Desenha os gráficos em tela ();

- UnloadContent() - Libera os recursos gráficos.

A parte principal do jogo estabelece a condição para que o jogo prossiga, ou seja, o movimento correto do usuário. Para isso, foram feitos cálculos que verificam se as posições estão corretas.

A cada interação entre o programa do jogo e o usuário, as seguintes funções são inicializadas:

- capturar os gestos do jogador;

- executar os cálculos necessários para validação dos movimentos;

- verificar se o critério de fim de jogo foi alcançado;

- desenhar gráficos em tela, gerar sons e respostas aos comandos do jogador;

- finalizar os gráficos, dispositivos de entrada e som.

O jogo termina quando o jogador, após realizar os movimentos corretos para movimentar a cadeira, ultrapassa a linha de chegada.

\section{Resultados}

No trabalho, foi realizada a construção do protótipo do jogo, utilizando a realidade virtual e o dispositivo Kinect, que através de sensores proporcionam uma interação mais eficiente entre o cadeirante e o jogo, possibilitando, além da inclusão social, uma opção a mais, para que estes deficientes físicos possam se movimentar, questão essencial e de extrema importância para pessoas portadoras de deficiência física.

O jogo funciona da seguinte forma: ao iniciar o jogo, aparece uma tela inicial, que possui três opções: Corrida, Recordes, e a opção Sair, que finaliza o jogo, conforme ilustrado na Figura 1.

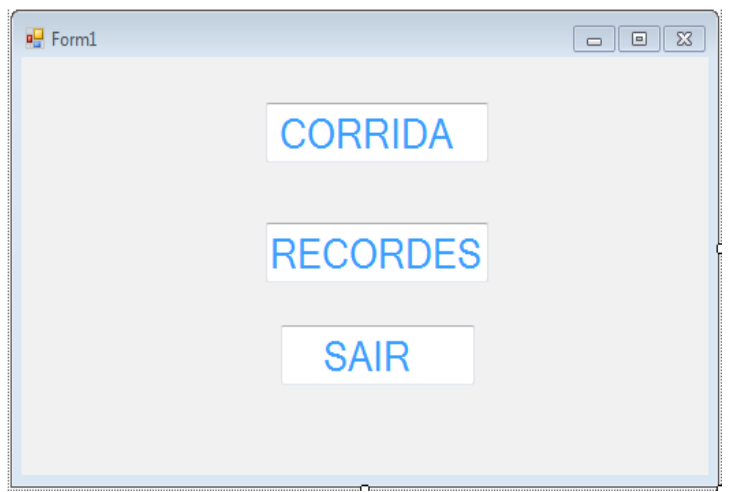

Figura 1: Tela inicial do jogo.

Ao escolher a opção Corrida, o jogador é redirecionado para uma pista de corrida para cadeirantes, assim, inicia uma contagem regressiva de três segundos e começa a corrida, como mostrado na Figura 2, com o usuário já no ambiente do jogo. Ao término da corrida, o usuário é direcionado novamente para o menu inicial.

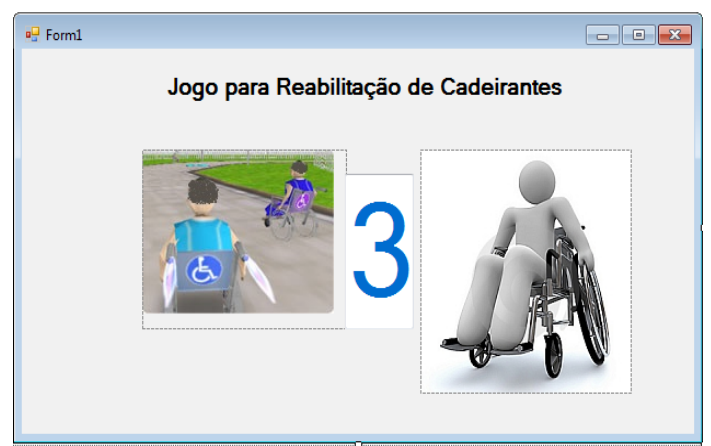

Figura 2: Início da corrida para cadeirantes.

Ao escolher a opção Recordes, o sistema exibe uma tela que mostra a data do jogo, bem como o tempo recorde que ele conseguiu finalizar a pista de corrida, apresentado na Figura 3.

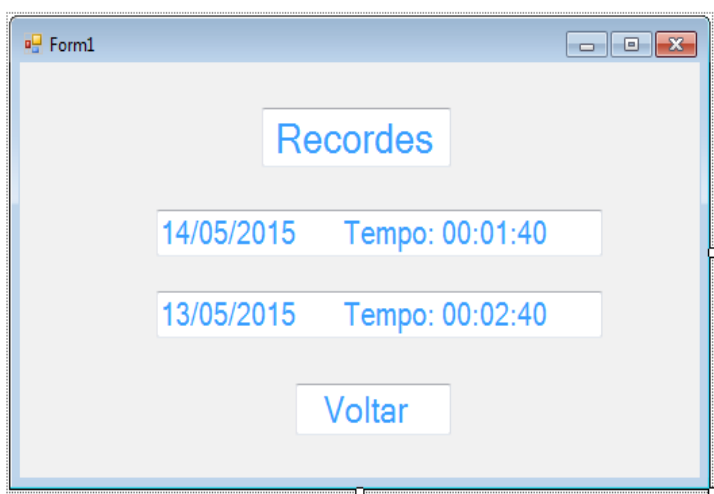

Figura 3: Tela de recordes do jogo.

Foi necessário habilitar a captura do esqueleto humano pelo Kinect, assim como o código necessário para conexão entre o Kinect e o programa. Também foi preciso criar um array do tipo esqueleto, atribuir dados a ele, verificar se está sendo monitorado, atribuir uma variável a parte do corpo que se pretende monitorar (nesse caso, as mãos), e criar a modificação desejada, ou seja, foi feita uma resposta quando a proximidade das mãos é alterada para frente.

Para captura do movimento, o sensor Kinect utilizou um código de programação. Assim, é possível realizar a sua leitura e enviar ao sistema. Então, é detectado o movimento do usuário necessário para que a cadeira possa se locomover na pista em direção à linha de chegada.

O movimento necessário para movimentação do corredor cadeirante na pista é o de movimentar a mão como se estivesse andando com uma cadeira de rodas, ou seja, colocar a mão retas verticalmente com o corpo, fechar a mão e movimentá-la para frente, repetindo os movimentos para locomoção no jogo.

Para detectar esse movimento de locomoção, foi necessário criar um algoritmo para rastrear os movimentos do cadeirante e comparar com os movimentos para o desenvolvimento do usuário no jogo. Foi criada uma classe para rastrear e identificar os gestos. Este gesto pode estar em três estados: não identificado, em execução e identificado. 
Para que os gestos sejam válidos, foi utilizado um cálculo, que faz uma análise do ângulo do braço para saber se está na posição correta de impulso da cadeira de rodas. Se a posição for válida, a cadeira de rodas se locomove no jogo por um espaço na pista, correspondente ao movimento, e assim, sucessivamente, até que se chegue ao seu final.

As Figuras 4 e 5 mostram interações entre o usuário e o serious game através do Kinect. Através da integração do Unity $3 D$ com o Kinect, foi possível fazer, de maneira eficiente, a captura dos movimentos do cadeirante e transmiti-la em tempo real para o jogo.

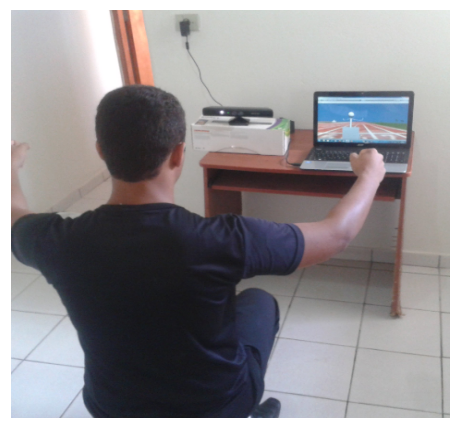

Figura 4: Interação entre o usuário e o jogo com as mãos inclinadas.

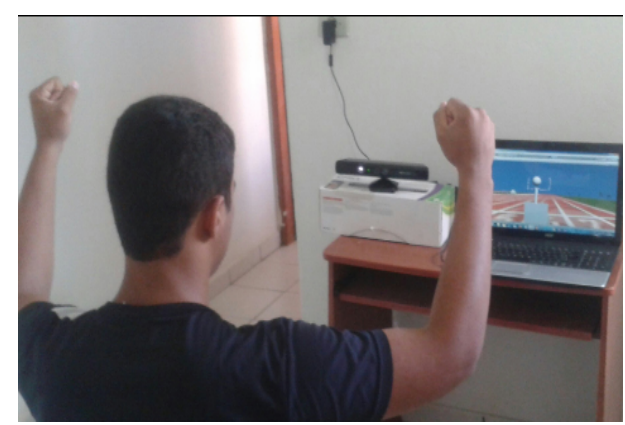

Figura 5: Interação entre o usuário e o jogo com as mãos para cima.

\section{Discussão}

Portanto, a inclusão social é algo que, a cada dia, ganha mais importância na sociedade, a preocupação com as pessoas com necessidade especiais não pode ser ignorada. Na mídia e no cotidiano, nota-se o esforço da população para que todos tenham acessibilidade em um mundo mais justo.

Os jogos ajudam na circulação e movimentação dos músculos, o que é algo essencial para os deficientes físicos, pois, se não houver algum tipo de movimento, os atos mais superficiais podem se tornar dolorosos para aqueles que não praticam algum tipo de atividade física.

Este serious game pode ser utilizado em qualquer lugar, desde centros de recuperação ou até mesmo na casa do usuário, desde que possua o Kinect e o software devidamente instalados.

\section{Conclusão}

Entendido o papel fundamental da tecnologia na vida do ser humano, em qualidade de vida, e a necessidade de adaptação e inclusão social de portadores com deficiência física, como foi mencionado, há o reconhecimento da necessidade do uso desta tecnologia para todos.

Logo, a aplicação, utilizando a tecnologia da Microsoft Kinect (sensores, câmeras, áudio, entre outros), apresentada nesse trabalho, possibilita que o deficiente físico, como o cadeirante, possa usufruir de um jogo adaptado para ele.

Além do usuário poder usufruir do jogo como forma de entretenimento, o jogo também tem como objetivo o tratamento da pessoa, que se verá livre da inércia, possibilitando assim mais agilidade, o que é de fundamental importância para os portadores de deficiência física, pois, para eles, dependendo da situação, simples movimentos como o calçar de uma meia ou pegar algum objeto torna-se uma tarefa árdua.

Percebe-se que este jogo traz contribuições significativas para a inclusão social do indivíduo e também para a reabilitação, uma vez que traz benefícios para o usuário.

Como trabalhos futuros, pretende-se aprimorar o sistema, para que essa experiência de jogar seja mais agradável possível e que traga cada vez mais benefícios para o portador de necessidades especiais.

\section{Agradecimentos}

Os autores agradecem o apoio e as orientações realizadas no Projeto de Iniciação Científica da Universidade de Uberaba por meio do Programa Institucional de Bolsas de Iniciação em Desenvolvimento Tecnológico e Inovação (PIBITI).

\section{Referências}

[1] Bersch R. Introdução à tecnologia assistiva. Porto Alegre: CEDI, 2008.

[2] Medeiros ACS. Interação Natural baseada em Gestos como Interface de Controle para Modelos Tridimensionais [dissertação]. João Pessoa: Universidade Federal da Paraíba; 2012.

[3] Kirner C, Sisccoutto R. Realidade virtual e aumentada: conceitos, projeto e aplicações. Livro do IX Symposium on Virtual and Augmented Reality, Porto Alegre: SBC, 2007. 202 p.

[4] Nunes MAS et. al. Uso do Kinect para a extração de características afetivas do usuário [tese]. São Cristóvão: Universidade Federal de Sergipe; 2011.

[5] Harma A et al. Techniques and applications of wearable augmented reality audio. In: Audio Engineering Society Convention Paper, Amsterdam, Holanda, 2003.

[6] Cardoso G. Biblioteca de Funções para Utilização do Kinect em Jogos Eletrônicos e Aplicações NUI. Vale do Itajaí. Universidade UNIVALI, 2012.

[7] Unity Technologies [internet]. Disponível em: https://unity3d.com/pt. Acesso em: março de 2016. 